\title{
Behavior of Corrosion of a Heat Pipe Cooling Device in a Computer
}

\author{
Sampan Rittidech \\ Heat Pipe and Thermal Tools Design Research Unit \\ Faculty of Engineering \\ Mahasarakham University \\ Thailand \\ s.rittidech@hotmail.com
}

\author{
Anuluk Rodbumrung \\ Heat Pipe and Thermal Tools Design Research Unit \\ Faculty of Engineering \\ Mahasarakham University \\ Thailand \\ A_Rodbumrung@hotmail.com
}

\begin{abstract}
The aim of this study was to perform life testing and to determine the effect of working time on the corrosion of a heat pipe used for cooling in a computer. The heat pipe was made from a copper tube. The heat pipe consists of evaporator and condenser section. It had a specification similar with the use in ordinary computers, the working fluid being distilled water. When the computer starts, the concentration of the copper solution slightly increases. The greater copper concentration was 0.00062 ppm upon 3000-5000 hours of testing. The surface traces of corrosion rises due to the oxidation of the porous material within the working fluid. The test found that oxygen $(O)$ and carbon (C) are component contents.
\end{abstract}

Keywords-heat pipe; computer; cooling; corrosion

\section{INTRODUCTION}

The advantage of heat pipe is that it can be used as cooling and heat exchange equipment, as an application for cooling of power electronics or communications devices. The heat pipes are usually made of metal, most common of which is copper and contain a porous material. After some time, corrosion will emerge within the heat pipes and porous materials. The corrosion mechanism of the heat pipe has been studied by many researchers. In [1], authors studied corrosion in a closedloop oscillating heat-pipe with check valves (CLOHP/CV) when water and ethanol were used as working fluids. They used scanning electron microscopy (SEM) and energy dispersive X-ray spectrometry (EDX), and found that the characteristics of the corrosion of the internal surface of the $\mathrm{CLOHP} / \mathrm{CV}$ were pitted. Analysis with atomic absorption spectroscopy (AAS) showed that ethanol had a higher concentration of copper particles than water. In [2], authors studied corrosion behavior in copper tube heat pipes with distilled water and ethanol as working fluids. The results of the scanning electron microscope and energy dispersive $\mathrm{X}$-ray spectrometry analysis showed that the corrosion of the heat pipe was uniform. The result of the atomic absorption spectroscopy indicated that the concentration of the copper in the ethanol as working fluid was greater than in the distilled water, and the highest concentration of copper particles in the ethanol was $22.7499 \mathrm{ppm}$ or $0.0409 \mathrm{mg}$ after testing for $3000 \mathrm{~h}$. The concentration of copper was higher when the length of the life test increased due to corrosion of the heat pipe. In [3], authors studied the failure of copper tubes in air conditioning. They found that the copper tube in air conditioning had ant-nest corrosion. The failure of the copper in the air-conditioning units caused the loss of refrigerant. The major causes of failure were moisture and oxygen. The need of studying the mechanisms and forms of corrosion and heat transfer of heat pipes cooling device in desktop computer emerged. To date, no such research has been done. This research will focus on the study of the heat transfer rate of heat pipes and corrosion affecting the use of heat pipe cooling device that uses a central processor unit (CPU) in a desktop computer.

\section{EXPLERIMENTAL PROCEDURE}

Corrosion occurs on the inner surface of a heat pipe, was made from a copper tube. The heat pipe's ID and OD are 4.48 $\mathrm{mm}$ and $6 \mathrm{~mm}$ respectively. Its length $295 \mathrm{~mm}$ consisted of an evaporator section of $35 \mathrm{~mm}$, condenser section of $190 \mathrm{~mm}$ and an adiabatic section of $70 \mathrm{~mm}$. The wick thickness was 0.24 $\mathrm{mm}$ and wick pore 0.5 . The heat pipe cooling device for testing is shown in Figure 1. The experimental setup and testing tools are shown in Figure 2, and the test rig is shown in Figure 3. This study consisted of a 4 set desktop computer with a heat pipe cooling device. The evaporator section was embedded in the CPU of the computer and the condenser section transfer heat by a fan system. The durations of testing were 500, 1000, 3000 and 5000 hours. The test heat pipe cooling system was measured with an hour meter, a temperature recorder, and a personal computer. The time was measured using the hour meter Kurber model 134, the ambient temperature was kept at $25^{\circ} \mathrm{C}$. Thermocouples (OMEGA type $\mathrm{K}$ ) were used to measure the temperature of the condenser sections. All the temperature data were recorded by a data logger (Yokogawa DX200) and then transferred to a personal computer.

1) The controlled parameters were:

- $\mathrm{CPU}=3.5 \mathrm{GHZ}$,

- Working fluids $=$ DI water.

2) The variable parameters were:

- Heat transfer rate 
- Effect of corrosion of the heat pipe on lifetime

3) Specifications

- Desktop computer

- Copper tube heat pipe with porous media, consists of fins

- Fan cooling system embedded to heat pipe system

- Temperature of CPU varies

- Fan speed of cooling system varies

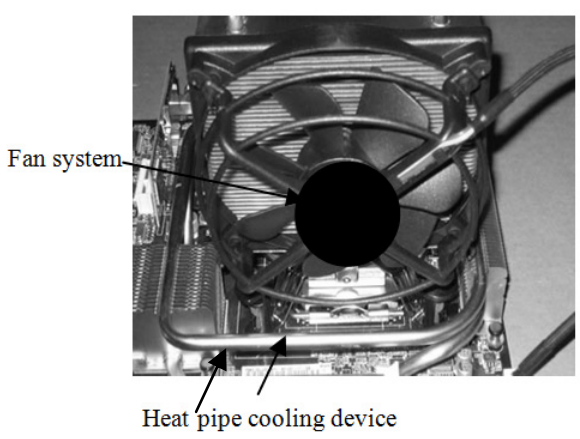

Fig. 1. Heat pipe cooling device.

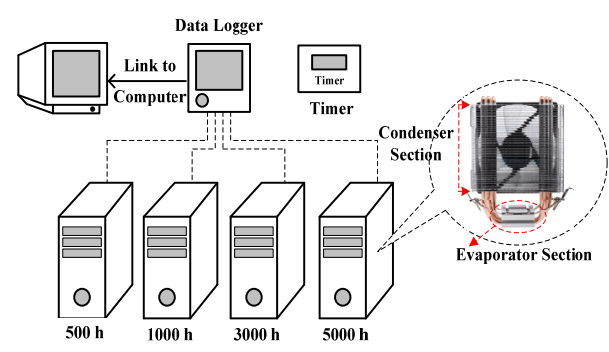

Fig. 2. Experimental set up.

\section{RESULTS AND DISCUSSION}

The cooling device operated under a steady temperature condition for $5000 \mathrm{~h}$. Then, there was an examination of the metallographic and preparation of specimens for the study of the inside of the pipe and wick. The composition of the heat pipe with a sintered wick composed of purified dendritic copper $(99.97 \%)$. The preparation specimens were cut into 10, 3 and $6 \mathrm{~mm}$ sections to be tested and analyzed by the SEM in order to identify the corrosion on the inside of the tube. The EDX identified the composition of the corrosion products from the inner heat pipe and wick. The working fluid within the heat pipe was DI water and the analysis of the concentration of the copper solution in the working fluid was done by the AAS. The results from the experiment are presented in Figures 4, 5 and 6. Figure 4 shows the effect of the concentration of the copper solution with corrosion occurred inside the heat pipe. The concentration of the copper solution slightly increases when the computer starts. The greater concentration of the copper is
0.00062 ppm after $3000-5000$ hours. This may be due to the fact of the oxidation reaction between the porous material and the working fluid. In any case, from 3000 to 5000 working hours, the concentrations of copper have similar values.

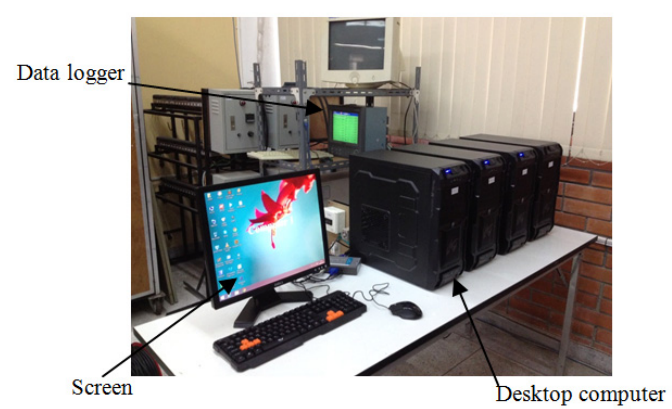

Fig. 3. Test rig.

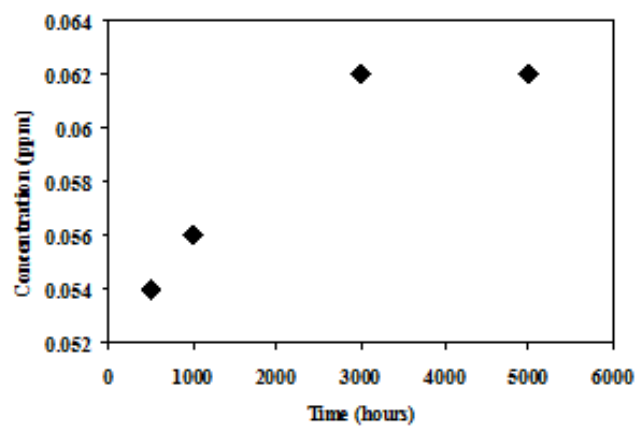

Fig. 4. Concentration of the copper solution.

In Figures 5 a-c we see the effect of surface corrosion inside the evaporator section of the heat pipe. After 500 hours, the test found traces of corrosion. Porous materials and powders are packed together noticeably. After 1000 hours of testing, the surface traces of corrosion are on the rise due to the oxidation of the porous material by the working fluid, thereby resulting in corrosion spreading up and delivery affecting the structure of spaces of porous structures. After 3000-5000 hours we found uneven traces of corrosion on the surface of the porous material. However, the operating temperature of the heat pipe is not very high. The changing nature of the internal structure of porous materials may see no clear effect of surface corrosion and the inside elements. Figures 6 a-c show the corrosion effect on the elemental content inside the evaporator section. The test found oxygen (O) and carbon (C) along with Copper $(\mathrm{Cu})$. This reaction is caused by corrosion of the internal working fluid. The amount of copper in the evaporator reduces when the test period is increased as we see with test periods of 5001000 and 3000-5000 hours, although the results did not find any other elements. This explains the process of creating a heat pipe with the removal of non-condensables and the use of water with lead ions as working fluid. Deionized water would cause the least corrosion. This will coincide with the results of the analysis from the AAS and the characteristics of the porous structure made from SEM results of the test period. 


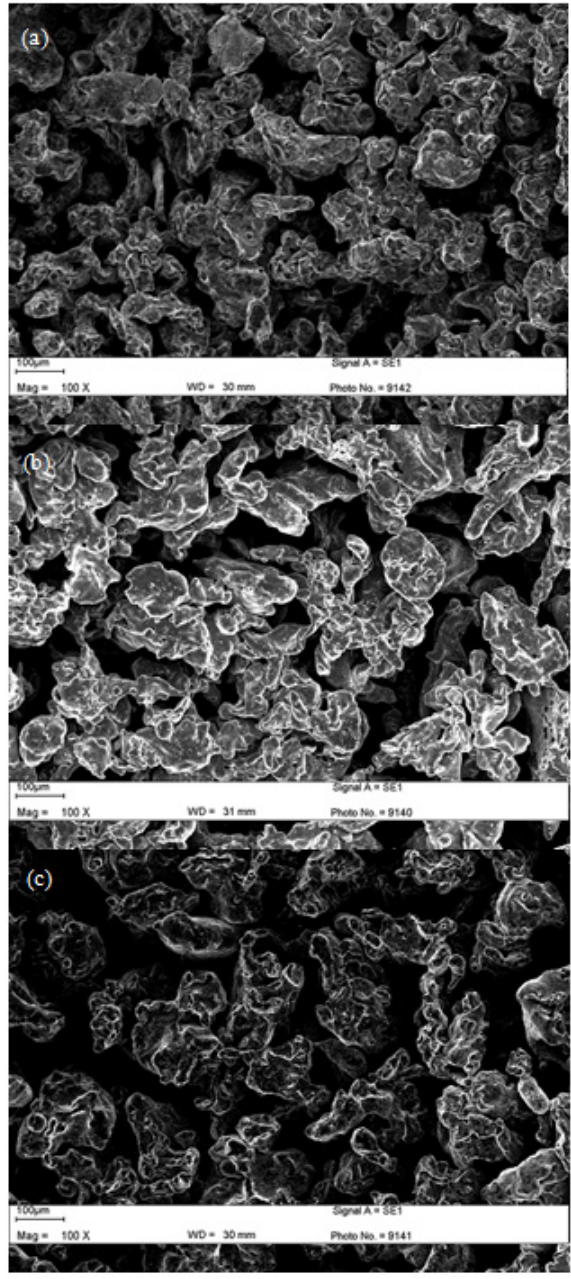

Fig. 5. Surface corrosion at (a) 500 hours (b) 1000 hours (c) 3000-5000 hours

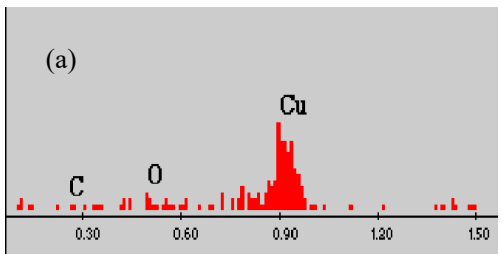

(b)

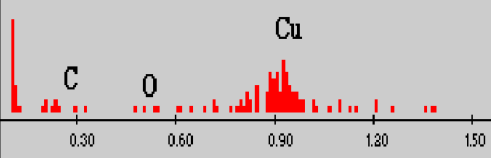

(c)

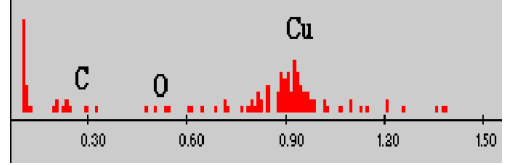

Fig. 6. Elemental content at (a) 500, (b) 1000 and(c) 3000-5000 hours

\section{CONCLUSIONS}

The concentration of the copper solution increases slightly when the computer starts. The greater concentration of the copper is $0.00062 \mathrm{ppm}$ after $3000-5000$ hours of testing. The surface traces of corrosion rise due to the oxidation of the porous material within the working fluid, resulting in the spreading up of the corrosion and the affecting of the structure of spaces of porous structures. As for the elemental content of the corrosion inside the evaporator section of the heat pipe, the test found oxygen and carbon as component contents.

\section{ACKNOWLEDGEMENT}

The authors wish to express their gratitude to the Project for Higher Education Research Promotion and National Research University Development and the Mahasarakham University for providing the necessary financial aid and the facilities to conduct the research.

\section{REFERENCES}

[1] S. Sangiamsuk, B. Bubphachot, S. Rittidech, O. Watanabe, "Corrosion mechanism in a closed-loop oscillating heat-pipe with check valves (CLOHP/CV)", Anti-Corrosion Methods and Materials, Vol.61, No. 5, pp. 293-299, 2014

[2] A. Rodbumrung, S. Rittidech, B. Bubphachot, "Corrosion behavior in heat pipe", Advances in Mechanical Engineering, Vol.8, No. 1, pp.1-9, 2016

[3] D. M. Bastidas, I. Cayuela, J. M. Bastidas, "Ant-nest corrosion of copper tubing in air-conditioning units", Revista de Metalurgia, Vol. 42, No. 5, pp. 367-381, 2006 